\title{
Surgical Treatment of Epilepsy in Pediatric Patients
}

\author{
Elaine Wyllie
}

\begin{abstract}
Surgery has become an accepted treatment modality for carefully selected adults with intractable focal epilepsy. More recently, increasing numbers of pediatric patients with intractable epilepsy are also being referred for surgical consideration. Key elements of surgical candidacy include medically intractable focal epilepsy, a localized epileptogenic zone, and a low risk for new postoperative neurologic deficits. The most common etiologies of the epilepsies in pediatric surgical candidates are malformation of cortical development and low grade tumor but some patients with childhood onset temporal lobe epilepsy due to hippocampal sclerosis also present for early surgery. Based on results from several recent pediatric surgical series, the chance for favorable seizure outcome after surgery is not adversely affected by young age, with seizure-free postoperative outcome reported for $60 \%$ to $65 \%$ of infants, $59 \%$ to $67 \%$ of children, and $69 \%$ of adolescents, compared to $64 \%$ reported in a large, predominantly adult series. Some subgroups of patients have higher percentages of seizure-free outcome, including those with hippocampal sclerosis or low grade tumor. In addition to seizures, developmental issues are also a major concern in children with intractable epilepsy. Few quantitative data are available, but some anecdotal experience suggests that surgical relief of catastrophic epilepsy may result in resumption of developmental progression after surgery, although the rate of development often remains abnormal. In one series, best developmental outcomes were seen in patients with earliest surgery and highest level of preoperative development. For each patient, the timing of surgery must be carefully considered, based on a full assessment of the relative risks and benefits, derived from a detailed presurgical evaluation.
\end{abstract}

RÉSUMÉ:Le traitement chirurgical de l'épilepsie chez les patients d'âge pédiatrique. La chirurgie est maintenant un traitement établi chez des patients adultes bien choisis qui présentent une épilepsie focale résistante au traitement. Plus récemment, un nombre de plus en plus considérable de patients d'âge pédiatrique présentant une épilepsie résistante au traitement sont également référés pour évaluation chirurgicale. Les critères de sélection de ces patients pour la chirurgie sont une épilepsie focale résistante au traitement médical, une zone épileptogène localisée et un risque faible d'induire des déficits neurologiques par la chirurgie. Les étiologies les plus fréquentes chez les candidats à la chirurgie d'âge pédiatrique sont les malformations du développement cortical et les tumeurs bénignes. Certains patients qui ont une épilepsie temporale débutant dans l'enfance due à une sclérose de l'hippocampe sont également référés à la chirurgie. Les résultats de plusieurs séries récentes de cas chirurgicaux pédiatriques démontrent que le jeune âge n'influence pas la probabilité d'une réponse favorable au traitement chirurgical, une disparition complète des crises étant rapportée chez 60 à $65 \%$ des nourrissons, 59 à $67 \%$ des enfants, $69 \%$ des adolescents par rapport à 64\% des adultes rapportés dans une série de patients en majorité adultes. Certains sous-groupes de patients, dont ceux qui ont une sclérose de l'hippocampe ou une tumeur bénigne, ont un meilleur pronostic chirurgical. En plus des crises, le développement est une préoccupation majeure chez les enfants présentant une épilepsie réfractaire au traitement. Il existe peu de données quantitatives, mais des expériences anecdotiques suggèrent que le traitement chirurgical d'une épilepsie catastrophique peut amener une reprise de la progression du développement après la chirurgie, même si la progression demeure souvent anormale. Dans une série, les meilleurs résultats au point de vue du développement étaient observés chez les patients qui avaient subi la chirurgie le plus tôt et qui avaient le niveau le plus élevé de développement avant l'opération. Le moment de la chirurgie doit être déterminé soigneusement en considérant tous les risques et les bénéfices à partir d'une évaluation détaillée de chaque patient avant la chirurgie.

Can. J. Neurol. Sci. 2000; 27: 106-110

Surgery has become an accepted treatment modality for carefully selected adults with intractable focal epilepsy. ${ }^{1-3}$ Infants and children may also benefit from epilepsy surgery, with encouraging results published in recent series. ${ }^{4-8}$ Key elements of surgical candidacy include medically intractable epilepsy, a localized epileptogenic zone, and a low risk for new postoperative neurologic deficits. This review will address some of the complex age-related issues that impact on the decision for epilepsy surgery in infants and children.

\section{ETIOLOGIES OF THE EPILEPSIES}

Hippocampal sclerosis is the most common etiology of the epilepsy in adult candidates for epilepsy surgery, but not in

From the Section of Pediatric Epilepsy, Department of Neurology, The Cleveland

Clinic Foundation, Cleveland, Ohio, USA.

RECEIVED OCTOBER 12, 1999. ACCEPTED IN FINAL FORM JANUARY 11, 2000.

Reprint requests to: Elaine Wyllie, Head, Section of Pediatric Epilepsy, Department of Neurology/S51, The Cleveland Clinic Foundation, 9500 Euclid Avenue, Cleveland,

Ohio 44195, USA. 
pediatric patients. Engel ${ }^{1}$ examined multicentre, predominantly adult data and found that $73 \%$ of 5446 epilepsy surgeries (excluding corpus callosotomies) were temporal resections in what he termed the nonlesional group, which included patients with hippocampal sclerosis. In contrast, hippocampal sclerosis was the etiology for only $15 \%$ of 74 adolescents and $12 \%$ of 62 preadolescent children in the pediatric epilepsy surgery series from The Cleveland Clinic Foundation. ${ }^{4}$ The most common etiologies among pediatric surgical candidates are low grade tumors and focal malformations of cortical development, which together accounted for the etiologies in $57 \%$ of the adolescents, $70 \%$ of the preadolescent children, and $90 \%$ of the infants in the Cleveland Clinic series. ${ }^{4}$ Similarly, Duchowny and colleagues ${ }^{5}$ reported low grade tumors or malformations of cortical development in $90 \%$ of the infants in the series from Miami Children's Hospital. Although hippocampal sclerosis may first manifest with seizures in early childhood, patients typically do not present for presurgical evaluation until late adolescence or early adulthood.

These differences in etiologies result in age-related differences in the types of surgeries performed to relieve the epilepsy. The most common epilepsy surgery in adults is anteromesial temporal resection. In infants and children, however, extratemporal or multilobar resections and hemispherectomies predominate. In the Cleveland Clinic series, ${ }^{4}$ these procedures comprised $44 \%$ of surgeries in adolescents, $50 \%$ of surgeries in children, and $90 \%$ of surgeries in infants. Similarly, $84 \%$ of infants had extratemporal resection or hemispherectomy in the series from Miami Children's Hospital. ${ }^{5}$ Compared to adults with hippocampal sclerosis, children with developmental anomalies and tumors tend to need more extensive surgical procedures to ameliorate their epilepsy.

\section{PotentIAL RISKS OF EPILEPSY SURGERY}

The most serious risk of epilepsy surgery is perioperative mortality. Isolated deaths were reported in several pediatric series, ${ }^{4,5,8,9}$ with a frequency of $1.3 \% .^{4}$ The risk may be higher in infants, because of their tendency to require extensive surgery in the face of a small blood volume. Especially in infants, it is critically important that epilepsy surgery be reserved for patients with severe epilepsy, and performed at specialized pediatric centers.

The mortality of epilepsy surgery must be balanced against the mortality of medically treated uncontrolled seizures. Nashef and colleagues ${ }^{10}$ estimated this risk to be 1:295/year among children and adolescents with developmental problems and uncontrolled seizures. Based on results in an adult series, ${ }^{11}$ elimination of seizures after surgery reduces mortality rates in people with epilepsy to a level indistinguishable from that of the general population. Therefore, as pointed out by Sperling et al, ${ }^{11}$ the long term risk of continued medical treatment appears to be higher than the risk of epilepsy surgery in suitable candidates.

Other risks of epilepsy surgery include new postoperative neurologic deficits. In this case, young age confers some advantages because of developmental plasticity. Resection of eloquent cortex may result in milder hemiparesis or language impairment when the surgery is performed in a young, developing brain, ${ }^{12}$ although deficits will still be present. In addition, when the brain matures in the presence of a congenital malformation or tumor, eloquent cortex may develop in atypical regions away from the lesion. ${ }^{13}$ These clinical points are illustrated in the following two cases.

\section{Patient \#1}

This boy presented for presurgical evaluation at nine months of age. After an uncomplicated full term delivery, he had onset of intractable daily seizures on the first day of life. Seizures occurred in clusters, with 10 to 30 over one to two days, followed by only a few seizures for three or four days. Seizures involved right arm and right leg clonic jerking with eye deviation toward the left, or opisthotonic posturing with stiffening and extension of all extremities.

The infant also had right hemiparesis and developmental delay. At nine months of age, Bayley Scales of Infant Development - Second Edition included a Mental Age Equivalent of five months and a Motor Age Equivalent of four months (Index Scores $<50$ for both). On the Developmental Profile II, the Full Scale IQ Estimate was 53. On observation, he was noted to alternate between periods of alertness and extreme irritability and fatigue. He had very little spontaneous movement of the right arm and leg. When he was alert, he smiled socially and babbled. He did not reach for objects but had good visual tracking. He exhibited no fine finger movements in either hand. He was unable to sit without support and bore no weight on legs.

Magnetic resonance imaging (MRI) at four months of age revealed a focal malformation of cortical development in the left posterior frontal lobe extending across the central sulcus into the anterior portion of the postcentral gyrus (Figure 1). 18-Fluorodeoxyglucose PET showed severe hypometabolism in the region of the lesion on MRI. Interictal EEG at nine months showed left central sharp waves maximum at the $\mathrm{C} 3$ electrode, and ictal EEG showed seizure onset in the same region (Figures $2 \mathrm{a}$ and $2 \mathrm{~b}$ ). MRI also revealed a band heterotopion in the subcortical white matter underlying the right superior and inferior parietal lobules, but EEG and PET abnormalities were confined to the region of the much more prominent left hemisphere lesion.

He had surgery at nine months of age. The extent of the left posterior frontal malformation was identified intraoperatively by visual inspection and stereotactic MRI. An EEG seizure was recorded over the lesion with intraoperative electrocorticography, and primary hand motor cortex was identified in the same area by intraoperative cortical stimulation. Postoperative MRI (Figure 3) showed complete resection of the lesion. Histopathologic analysis of resected tissue revealed cortical dysplasia.

A single seizure occurred within 24 hours after surgery, followed by freedom from seizures for 26 months. Seizures returned after antiepileptic medications were discontinued, but then came under control when restarted on clobazam and oxcarbazepine. On EEG the seizures appeared to arise from the right hemisphere.

The right hemiparesis worsened slightly for a few days after surgery and then motor function returned to preoperative baseline. At 23 months of age, he could sit independently and bear weight on both legs, but he did not yet walk or crawl. He played with toys using the left hand more than the right, and had no fine finger movements in the right hand. He babbled frequently but had no intelligible words. He was very alert, sociable, and interactive. On the Bayley Scales of Infant Development Second Edition, Mental Age Equivalent was nine months and Motor Age Equivalent was 10 months (Index Scores $<50$ for both). The Vineland Adaptive Behavior Composite was 61 (age equivalent 11 months).

This case illustrates several points. The boy still had right hemiparesis, as expected, after resection of primary motor cortex; but at follow up this was not apparently worsened by the surgery. He made developmental progress after surgery, but his rate of developmental progression remained abnormal and at 23 months his cognitive and motor skills were still significantly delayed. His developmental delay may be due to his congenital brain malformation, independent of the surgery. What cannot be known is whether his developmental progress would have been slower still if he had not had surgery, as a result of 
continued exposure to frequent seizures throughout the period between 9 and 23 months of age.

Malformations of cortical development may be more extensive than the gross lesion seen on MRI, lowering the likelihood for complete freedom from seizures after surgery. ${ }^{4}$ In this case, the preoperative MRI provided a clue to the presence of malformation at a distance from the surgical site, and seizures later evolved from that area. However, resection of the more prominent and actively epileptogenic lesion gave him relief from his catastrophic epilepsy, and the subsequent seizures were much easier to control.

\section{Patient \#2}

This boy presented for presurgical evaluation at 15 years of age. Since five years of age, he had one to three seizures each day with an aura (tingling feeling in the head) evolving to decreased awareness, decreased responsiveness, gestural automatisms involving the left hand, and dystonic posturing of the right hand. Seizures were followed by transient dysphasia. Neurologic examination was normal, and he was an honors student in high school. He was right handed.

MRI revealed a left posterior temporal tumor (Figure 4). EEG showed interictal sharp waves in the left anterior and posterior temporal regions. EEG seizures were localized to the left temporal lobe. The intracarotid amobarbital procedure at 15 years of age gave evidence suggesting bilateral language representation. The boy was studied with subdural electrodes, which revealed onset of seizures in the region of the tumor. Functional mapping with cortical stimulation of subdural electrodes revealed that the posterior temporal language area was just behind the posterior margin of the tumor. He had complete resection of the tumor at 15 years of age, with seizure-free outcome and no impairment of language function reported subjectively by the patient or his parents. Histopathologic analysis showed that the lesion was an oligodendroglioma.

This case illustrates the role of developmental plasticity. Seizures began at five years of age, and at that time the tumor was already present

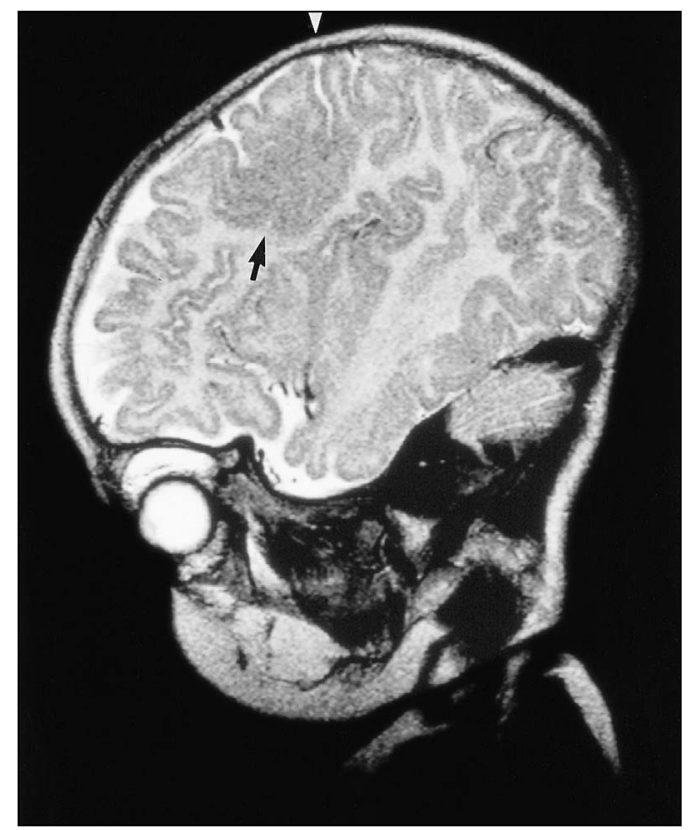

Figure 1: Patient \#1. Sagittal MRI, fast T2-weighted images (TR 4000, TE 99). The left posterior frontal malformation of cortical development (black arrow) extended posteriorly across the central sulcus (white arrow).

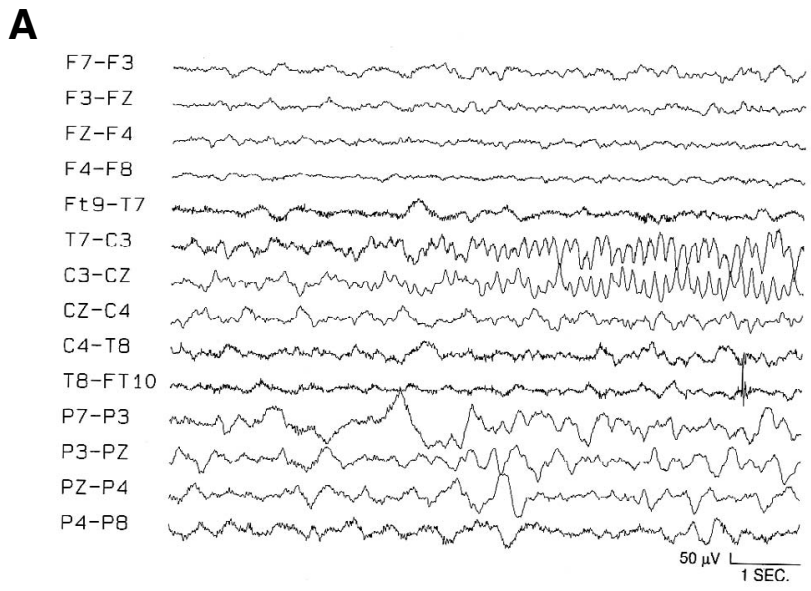

B

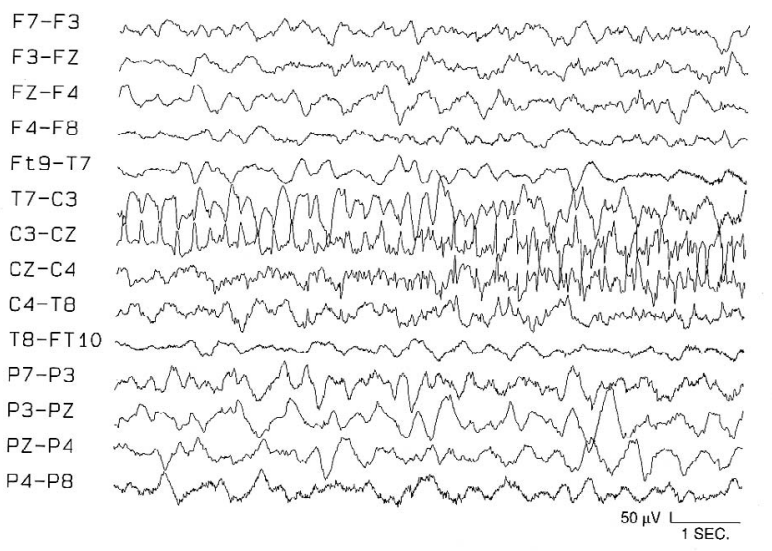

Figure 2: Patient \#1. 2a. Ictal EEG showing seizure onset in the left central region, maximum at the $C 3$ electrode. $2 b$. Ten seconds after onset, with EEG seizure spreading to involve $C z$ as well as $C 3$.

on MRI. Ten years later, the mass had not increased in size. It is likely that the tumor was present for some time before seizures began, during the period of language development. Although the tumor was in the usual region of Wernicke's area, the boy's language function was normal. In the presence of the tumor, language developed more posteriorly in the left hemisphere and also in the right hemisphere. Because of this, the tumor could be completely removed without causing a new language deficit. A similar tumor invading the same area later in life, after language had developed in the usual region, would probably have caused dysphasia.

\section{SEIZURE OUTCOME AFTER SURGERY}

For carefully selected patients, epilepsy surgery offers a significant chance for freedom from medically intractable seizures. In several pediatric surgical series published since 1997 , the percentage of patients with seizure-free outcome were $60 \%$ to $65 \%$ for infants, ${ }^{4-6} 59 \%$ to $67 \%$ for children, ${ }^{4,7}$ and $69 \%$ for adolescents. ${ }^{4}$ These results are similar to those reported in a large multicenter predominantly adult study, ${ }^{1}$ with $64 \%$ of patients seizure-free. Therefore, the chance for favorable seizure outcome after surgery does not appear to be adversely affected by young age. In addition to the seizure-free group, another $11 \%$ 

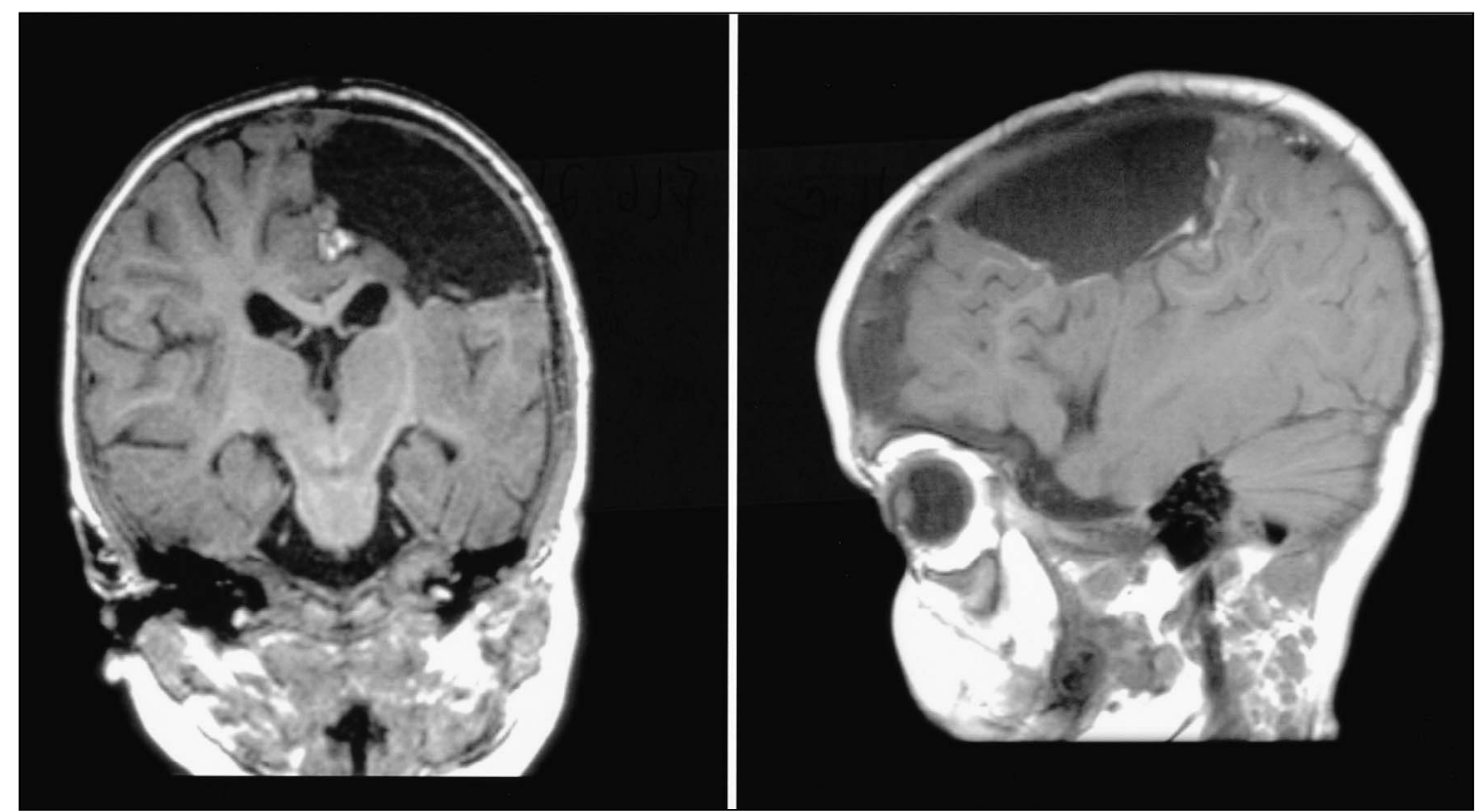

Figure 3: Patient \#1. Coronal (left image, TR 11.4, TE 4.4) and saggital (right image, TR 500, TE 12) MRI performed two days after the cortical resection performed at nine months of age.

to $20 \%$ of pediatric patients had only rare seizures after surgery. ${ }^{4-7}$

Some subgroups of patients may be more likely than others to have seizure-free outcome after epilepsy surgery. In the Cleveland Clinic pediatric series, ${ }^{4}$ significantly more patients were free of seizures after temporal resection $(78 \%)$ than after extratemporal or multilobar resection $(54 \%)$, with intermediate results after hemispherectomy (69\%). However, this difference based on surgery type disappeared when results were analyzed by etiology. Seizure-free outcome was signficantly more frequent when the etiology was tumor $(82 \%)$ than when it was cortical dysplasia (52\%), and this difference persisted whether the resection was temporal or extratemporal/multilobar. Results were intermediate for hippocampal sclerosis $(67 \%)$, but patient numbers in this group were small. In a larger, partially overlapping series of 34 children and adolescents who had surgery at the same institution for intractable temporal lobe epilepsy due to hippocampal sclerosis, $78 \%$ were seizure-free, ${ }^{14}$ and these results are similar to those in adults.

The presence of a focal lesion on MRI appears to be a favorable prognostic feature. In a predominantly adult series, ${ }^{15}$ seizure-free outcome was signficantly more frequent for lesional than nonlesional patients. Similar findings were reported in a pediatric surgical series. ${ }^{4}$ A positive MRI may enhance the chance for favorable seizure outcome by providing clear visual evidence for the location and extent of resection.

\section{DEVELOPMENTAL OUTCOME AFTER EPILEPSY SURGERY}

In adults, the usual goals for epilepsy surgery include obtaining driving privileges, achieving independence, and maintaining employment. To accomplish these goals, it is necessary for the patient to be free of seizures after surgery. ${ }^{16}$ In infants and children, the goals may be somewhat different and may include relief of catastrophic epilepsy, resumption of developmental progression, and improvement in disordered behavior. Developmental concerns are often paramount for infants and young children with intractable epilepsy.

Onset of seizures before two years of age is a risk factor for subsequent mental retardation. ${ }^{17}$ Among 100 epilepsy surgery candidates studied at The Cleveland Clinic Foundation by Vasconcellos et al, ${ }^{18}$ younger ages at seizure onset were associated with lower Full Scale IQ scores, and mean Full Scale IQ was significantly lower for patients with onset of epilepsy at $\leq 24$ months of age versus patients with onset of epilepsy later in life. The risk based on early age at seizure onset was greatest for children with daily seizures, and persisted within subgroups of patients with focal malformation of cortical development, tumor, or hippocampal sclerosis. Although the effect of the underlying cause of the epilepsy cannot be discounted, it is speculated that frequent, uncontrolled seizures may have a deleterious effect during critical stages of brain development.

An adverse effect of frequent seizures on early brain development would not be surprising in light of the complex maturational changes underway in the first two years of life. ${ }^{19} \mathrm{At}$ birth the normal brain weight is only $25 \%$ of that expected in adulthood, and by two years of age it is already $75 \% .^{20}$ This growth period is characterized by extensive dendritic arborization, dendritic spine formation, and synaptogenesis, ${ }^{21}$ each of which process may adversely be affected by ictal activity. ${ }^{22}$ In addition to the adverse effects on development of the underlying etiology of the epilepsy and the frequency of uncontrolled seizures, toxicity of high doses of antiepileptic medications may also play a role. ${ }^{23}$

In the series of infants who had epilepsy surgery at the Miami Children's Hospital, ${ }^{5} 80 \%$ of candidates had moderate or severe 


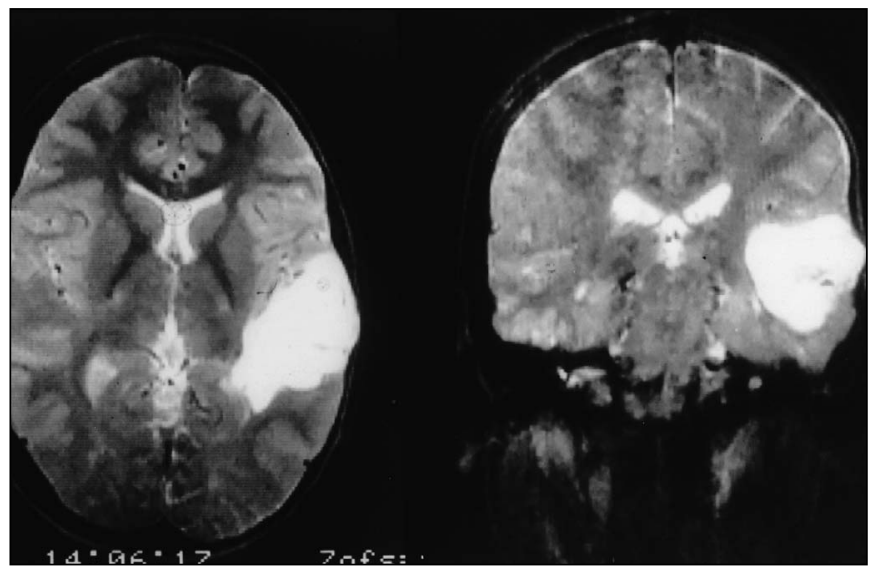

Figure 4: Patient \#2. Axial (left image) and coronal (right image) T2weighted MRI showing the left posterior temporal tumor.

mental retardation. This high percentage may reflect the nature of the underlying pathologic processes, the adverse effects of the catastrophic epilepsy, or both. Normal or severely impaired groups did not change postoperatively, but parents often noted cognitive and social gains which were difficult to confirm on examination. Some quantitative data are available from Asarnow and colleagues, ${ }^{24}$ who studied preoperative and two year postoperative neuropsychological test results in 24 patients who had epilepsy surgery after presenting with infantile spasms. They found that patients made developmental progress after surgery, reflected in a significant increase in mean raw scores on the Vineland Adaptive Behavior Scales. However, only four infants had a normal rate of development. Best developmental outcomes were seen in patients with earliest surgery and highest level of preoperative development, suggesting that shorter duration of seizures until surgery may lead to better long-term cognitive outcome. Additional data are needed to clarify the optimum age for surgical intervention in pediatric patients with catastrophic epilepsy.

Other psychosocial issues may also play a role in the timing of epilepsy surgery. Amelioration of intractable epilepsy before adolescence may facilitate the normal developmental transition into adulthood, providing the greatest chance for full independent living, employment, and marriage. It has been suggested that postponement of surgery until mid-adulthood may result in some irreversible psychosocial disabilities. These concerns have led to increased interest in earlier epilepsy surgery.

\section{ConClusions}

At epilepsy surgery centers, the interval between onset of intractable epilepsy and referral for presurgical evaluation is still fairly long, typically 10 to 15 years. Increasingly, efforts are being made to identify appropriate surgical candidates earlier in life. For each patient, the timing of surgery must carefully be considered based on a full assessment of the relative risks and benefits, derived from a detailed presurgical evaluation. For carefully selected children with severe, intractable epilepsy, a localized epileptogenic zone, and a relatively low risk for new postoperative neurologic deficits, early surgery may be an appropriate option.

\section{REFERENCES}

1. Engel J Jr. Surgery for seizures. N Engl J Med 1996; 334(10):647652.

2. Lüders HO. Epilepsy Surgery. New York, NY: Raven Press, 1992.

3. Engel J Jr. Surgical Treatment of the Epilepsies. New York, NY: Raven Press, 1993.

4. Wyllie E, Comair YG, Kotagal P, et al. Seizure outcome after epilepsy surgery in children and adolescents. Ann Neurol 1998; 44:740-748.

5. Duchowny M, Jayakar P, Resnick T, et al. Epilepsy surgery in the first three years of life. Epilepsia 1998; 39(7):737-743.

6. Chugani HT, Shewmon DA, Shields WD, et al. Surgery for intractable infantile spasms: neuroimaging perspectives. Epilepsia 1993; 34:764-771.

7. Paolicchi JM, Jayakar P, Dean P, et al. The outcome of focal resections in preadolescent children with intractable partial epilepsy. Neurology, in press.

8. Vining EPG, Freeman JM, Pillas DJ, et al. Why would you remove half a brain? The outcome of 58 children after hemispherectomy - The Johns Hopkins Experience: 1968-1996. Pediatrics 1997; 100(2):163-171.

9. Chugani HT, Shewmon DA, Peacock WJ, et al. Surgical treatment of intractable neonatal-onset seizures: the role of positron emission tomography. Neurology 1988; 38:1178-1188.

10. Nashef L, Fish DR, Garner S, Sander JWAS, Shorvon SD. Sudden death in epilepsy: a study of incidence in a young cohort with epilepsy and learning difficulty. Epilepsia 1995; 36(12):11871193.

11. Sperling MR, Feldman H, Kinman J, Liporace JD, O'Connor MJ. Seizure control and mortality in epilepsy. Ann Neurol 1999; 46(1):45-50.

12. Peacock WJ, Comair Y, Chugani HT, Shewmon DA, Shields WD. Epilepsy surgery in childhood. In: Luders HO, ed. Epilepsy Surgery. New York, NY: Raven Press, 1991: 589-598.

13. DeVos K, Wyllie E, Geckler C, Kotagal P, Comair Y. Language dominance in patients with early childhood tumors near left hemisphere language areas. Neurology 1995; 45:349-356.

14. Mohamed A, Wyllie E, Ruggieri P, et al. Temporal lobe epilepsy due to hippocampal sclerosis in pediatric candidates for epilepsy surgery: histopathology and seizure outcome. Submitted.

15. Zentner J, Hufnagel A, Ostertun B, et al. Surgical treatment of extratemporal epilepsy: clinical, radiologic, and histopathologic findings in 60 patients. Epilepsia 1996; 37:1072-1080.

16. Sperling MR, Saykin AJ, Roberts FD, French JA, O'Connor MJ. Occupational outcome after temporal lobectomy for refractory epilepsy. Neurology 1995; 45:970-977.

17. Huttenlocher PR, Hapke RJ. A follow-up study of intractable seizures in childhood. Ann Neurol 1990; 28:699-705.

18. Vasconcellos E, Wyllie E, Sullivan S, et al. Mental retardation in pediatric candidates for epilepsy surgery: the role of early seizure onset. Submitted.

19. Purpura DP. Dendritic differentiation in human cerebral cortex: normal and aberrant developmental patterns. In: Kreutzberg GW, ed. Advances in Neurology. New York, NY: Raven Press, 1975: 91-134.

20. Dobbing J, Sands J. Quantitative growth and development of human brain. Arch Dis Child 1973; 48:757-767.

21. Peacock WJ. Hemispherectomy for the treatment of intractable seizures in childhood. Neurosurg Clin N Am 1995; 6:549-563.

22. Collins RC, Olney JW, Lothman EW. Metabolic and pathologic consequences of focal seizures. Res Publ Assoc Nerv Ment Dis $1983 ; 61: 87-107$.

23. Bourgeois BFD, Prensky AL, Palkes HS, Talent BK, Busach SG. Intelligence in epilepsy: a prospective study in children. Ann Neurol 1983; 14:438-444.

24. Asarnow RF, LoPresti C, Guthrie D, et al. Developmental outcomes in children receiving resection surgery for medically intractable infantile spasms. Dev Med Child Neurol 1997; 39(7):430-440. 